\title{
Quaxterly Percutaneous biliary intervention: tips and tricks
}

\author{
Abanti Das, Vinit Baliyan, Shivanand Gamanagatti, \\ Arun Kumar Gupta
}

ABSTRACT

Department of Radiodiagnosis,

Percutaneous biliary intervention encompasses diagnostic cholangiography, which is rarely used in isolation now, and therapeutic biliary drainage including percutaneous transhepatic biliary drainage and transhepatic cholecystostomy. With the advantage of being minimally invasive and hence, relatively atraumatic, this technique has made significant foray into management of biliary obstruction (both benign and malignant) and post-surgical biliary complications. This review focuses on the key technical aspects of the procedure along with the commonly anticipated complications that have a significant bearing on the outcome. The authors, thereby, attempt to add their own experience to the existing literature about the various tricky situations that may be encountered during the course of the procedure and tips to circumvent them.

KEYWORDS: Percutaneous biliary drainage; biliary stricture; complications; percutaneous biliary stent; bile leak.

\section{Introduction}

Percutaneous biliary intervention includes diagnostic cholangiography and therapeutic biliary drainage in the form of percutaneous transhepatic biliary drainage (PTBD) and percutaneous cholecystostomy. With the advent of endoscopic retrograde cholangiopancreatography (ERCP) and non-invasive imaging modality i.e. magnetic resonance cholangiopancreatography (MRCP) for diagnostic evaluation of biliary obstruction, percutaneous cholangiography is rarely used in isolation these days. It essentially forms a preliminary step in the technique of percutaneous biliary intervention to outline the biliary anatomy before subsequent manipulation.

There are exhaustive details in literature documenting the technique of percutaneous biliary interventions including their indications, detailed procedural steps, anticipated complications and their remedies. This review, however, attempts to focus on the key technical aspects, which significantly influence the outcome of the procedure along with offering tips to come out of tricky situations, that one may come across, 
not only during the procedure but also during subsequent follow-up.

\section{Percutaneous Transhepatic Biliary Drainage (PTBD)}

Percutaneous biliary drainage entails primary therapeutic or palliative drainage of bile in patients with biliary obstruction. ${ }^{1}$ The recommended indications of PTBD are shown in Table $1 .^{1-3}$. Currently, it is predominantly used in cases where endoscopic route of biliary drainage has either failed or is not feasible as in cases with biliary enteric anastomosisdue to altered anatomy. ${ }^{4}$

\section{Choice of patient}

Although, the recommended indications are many, as outlined above, the principal role of percutaneous biliary drainage is palliation in cases of inoperable malignant biliary obstruction either due to advanced disease stage or due to patient-related co-morbidities. However, in this context it is important to remember that patients with very poor general condition (Eastern Co-operative Oncology Group ECOG) status $>2$ and those with advanced multisegmental biliary obstruction will not benefit significantly from the palliative role of PTBD.

\section{Site of obstruction}

The site of biliary obstruction and the underlying etiology (cholangiocarcinoma, gall bladder carcinoma infiltrating the hilum, periampullary carcinoma, metastatic lymph nodes or others) needs to be evaluated prior to the procedure. All the previous imaging of the patient should, therefore, be reviewed before scheduling the appointment. The basic aim is to classify the site of biliary obstruction as proximal or distal as this not only determines the preferred route of access but also the technical ease of the procedure. It is pertinent to revise the BismuthCorlette classification of malignant biliary strictures in this regard (Table 2). For distal biliaryobstruction, which includes periampullary carcinoma or lower end cholangiocarcinoma, an endoscopic route is preferred. However, for proximal biliary obstruction including

\section{Table 1: Indications of PTBD}

\begin{tabular}{|c|c|}
\hline S.No & Indications of PTBD \\
\hline 1. & $\begin{array}{l}\text { Adequate biliary drainage or diversion with or } \\
\text { without stent placement }\end{array}$ \\
\hline \multirow[t]{2}{*}{2.} & Establish biliary access to \\
\hline & $\begin{array}{l}\text { - Dilate biliary strictures } \\
\text { - Remove bile duct stones } \\
\text { - Stent placement } \\
\text { - Brachytherapy/phototherapy } \\
\text { - Endoluminal tissue sampling/foreign body retrieval. }\end{array}$ \\
\hline 3 & Manage post-operative complications \\
\hline & $\begin{array}{l}\text { - Failed pancreatico-jejunostomy anastomosis } \\
\text { - Failed bilio-enteric anastomosis } \\
\text { - Duodenal stump insufficiency } \\
\text { - Post-operative leak from extrahepatic bile ducts }\end{array}$ \\
\hline
\end{tabular}

Table 2: Bismuth-Corlette classification of malignant biliary strictures

\begin{tabular}{l|l} 
Type & Description \\
\hline I & Involving common hepatic duct (CHD) \\
\hline II & $\begin{array}{l}\text { CHD and confluence of right hepatic duct (RHD) } \\
\text { and left hepatic duct (LHD) }\end{array}$ \\
\hline IIIA & CHD, primary confluence and RHD \\
\hline IIIB & CHD, primary confluence and LHD \\
\hline IV & $\begin{array}{l}\text { CHD, primary confluence, involving both RHD } \\
\text { and LHD }\end{array}$
\end{tabular}

hilar cholangiocarcinoma (Bismuthtype II and above), percutaneous route is the preferred choice of biliary drainage. In addition, failed ERCP stenting in distal obstruction and post-surgical candidates with biliaryenteric anastomosis are alsosuitable candidates for percutaneous drainage.

\section{Choice of percutaneous access site}

The basic premise of establishing percutaneous drainage is to drain maximum liver volume with minimal extraneous catheters or stents, although in clinical practice, drainage of at least $25 \%$ of liver parenchyma is sufficient to relieve jaundice and pruritus. ${ }^{5}$ Hence, the need to judiciously select the puncture site.

The left hepatic duct has a longer course before secondary confluence with fewer side-branches. So, when 
unilateral drainage is planned for Bismuth type II (hilar) and type III biliary strictures, left-sided approach offers better drainage of larger volume of hepatic parenchyma (Figure 1).

Sometimes, a lobe of liver may undergo atrophy due to associated encasement of portal vein branches by the tumour, hence draining that lobe may not alleviate the patient symptoms or salvage any significant liver function. It is imperative in such cases to drain the spared lobe (Figure 2).

Depending upon the clinical scenario, the biliary system may be accessed through the right or the left sided duct, each with its own advantages and disadvantages. Table 3 summarizes important technical differences between the two approaches. ${ }^{4}$

\section{Pre-procedural Screening}

Pre-procedural preparation involves reviewing coagulation profile of the patient which includes baseline hematocrit, platelet count and prothrombin time/ international normalized ratio (PT/INR) and activated partial thromboplastin time (a PTT in patients receiving intravenous unfractionated heparin infusion). Any derangement in the above-mentioned parameters needs to be corrected (INR to be reduced to $<1.5$ using fresh frozen plasma (FFP) or vitamin $\mathrm{K}$, platelet count less than $50,000 / \mu \mathrm{L}$ to be corrected by transfusion $\left.{ }^{6}\right)$. Baseline renal function tests (blood urea nitrogen and creatinine) also needs to be checked before administration of iodinated contrast.

While screening previous imaging of the patient, care should be taken to look for any aberrant anatomy of the biliary tree, which is common. Normally, segment 6 and 7 ducts join to form right posterior sector duct (RPSD) while segment 5 and 8 ducts join to form right anterior sector duct (RASD). The RASD and RPSD join to form right hepatic duct (RHD) which then joins left hepatic duct (LHD) to form common hepatic duct (CHD). ${ }^{7}$

In about $23 \%$ of cases RPSD joins LHD, while in about 5\% cases RASD joins LHD-anomalous variants which need to be identified prior to the procedure as these patients are better suited for left-sided drainage which would not only drain the left lobe as well as part of the
A

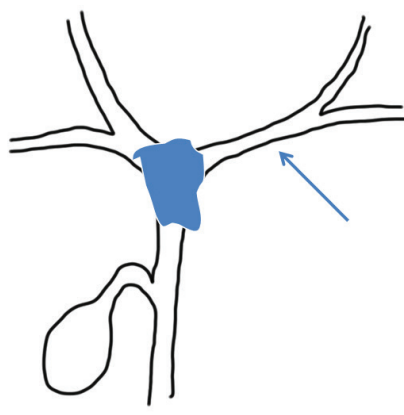

B

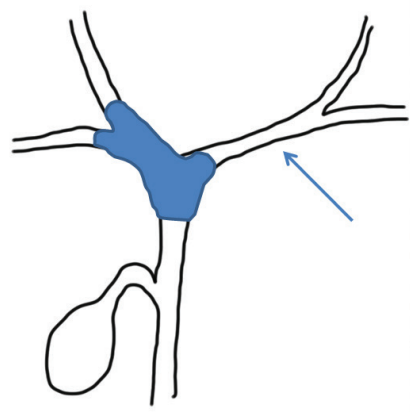

Figure 1: Schematic diagram showing preferred left hepatic duct puncture in Bismuth type 2. (A): and 3 (B): stricture due to its longer course.
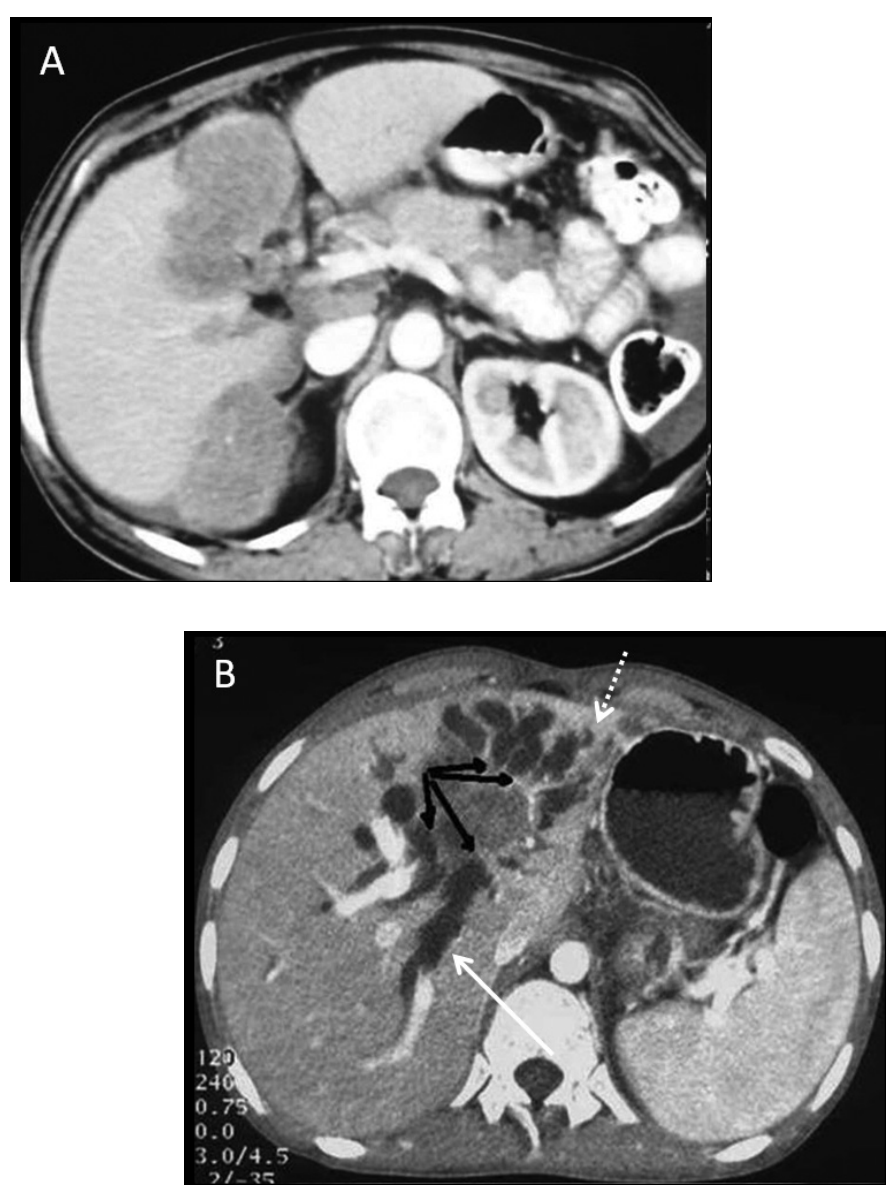

Figure 2: (A and B): Carcinoma gall bladder with contiguous infiltration of hepatic hilum (clustered black arrows in B). Left lobe of liver is atrophied (dashed white arrow in B) with crowding of dilated biliary radicals. In such cases, it is preferable to drain the contralateral right lobe with relatively preserved volume (solid white arrow in B). 
Table 3: Comparison of right-sided and left-sided puncture for PTBD

\begin{tabular}{|c|c|c|c|}
\hline S.No. & Features & Right-sided puncture & Left-sided puncture \\
\hline 1 & Patient comfort & Painful,restricted patient movement. & $\begin{array}{l}\text { Less painful, Increased patient } \\
\text { comfort. }\end{array}$ \\
\hline 2 & Technical ease of puncture & Difficult & Easy \\
\hline 3 & Associated risk & $\begin{array}{l}\text { Pleural transgression, injury to } \\
\text { intercostal neurovascular bundle }\end{array}$ & - \\
\hline 4 & Radiation exposure & Less radiation to operator & $\begin{array}{l}\text { Higher radiation exposure to } \\
\text { operator's hands }\end{array}$ \\
\hline 5 & Preferred duct & Anterior sectoral duct & $\begin{array}{l}\text { Segment three duct- antero-inferior to } \\
\text { segment twoduct. }\end{array}$ \\
\hline 6 & Puncture site & Below 10th rib at mid-axillary line & Subxiphoid or substernal. \\
\hline 7 & Imaging guidance for puncture & $\begin{array}{l}\text { Blind puncture with fluoroscopic } \\
\text { guidance }\end{array}$ & Ultrasonographic guidance \\
\hline
\end{tabular}

right lobe, establishing drainage of most of the liver parenchyma (Figure 3). This especially applies to patients with periportal metastatic disease with higher chances of multisegmental ductal obstruction. ${ }^{7}$

Pre-procedural screening also entails assessment of liver size and morphology as well as presence or absence of ascites. Although not an absolute contraindication, presence of ascites makes the procedure technically challenging. Fluid interposed between liver surface and abdominal wall makes manipulation of catheters and guidewires difficult increasing the risk of bleeding from liver capsule and biliary peritonitis. ${ }^{8}$ If sonographic assessment reveals gross ascites with fluid all around liver, it needs to be drained prior to the procedure. However, in cases of moderate ascites with no rim of fluid around the left lobe, left-sided access should be obtained, preferably in a single puncture of liver capsule to prevent complications.

\section{Choice of hardware}

Choice of appropriate hardware depends on the radiologists' preference. However, as a general rule, in cases with minimally dilated biliary system for examplebiliary leaks or biliary-enteric anastomotic strictures, smaller gauge puncture needle is to be used (Micropuncture set, Neff mini-access set or $22 \mathrm{G}$ Chiba needle) which can accommodate a 0.018 inch guidewire.
A

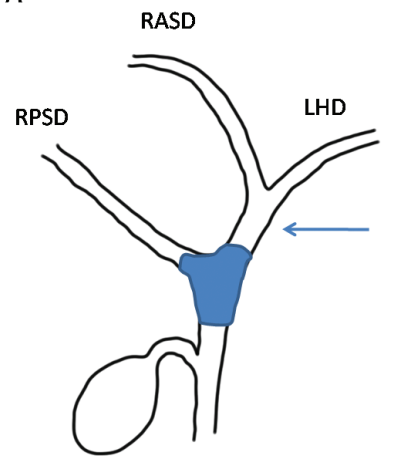

B

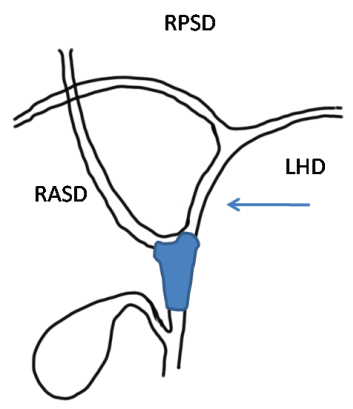

Figure 3: (A and B): Schematic diagram showing preferred left hepatic duct puncture in aberrant anatomy of biliary radicals allowing drainage of larger volume of hepatic parenchyma.

However, for grossly dilated biliary system as seen in malignant biliary obstruction, $18 \mathrm{G}$ puncture needle can be used which can accommodate a 0.032 inch or 0.035 inch guidewire.

\section{Tips during puncture}

\section{Judicious use of fluoroscopy}

The first step to successful PTBD is to secure a proper percutaneous access to the biliary tree, which usually requires combined ultrasound and fluoroscopic guidance 
for real time visualization of needle, and guidewire manipulation. Cumulative fluoroscopy time may vary considerably depending upon the complexity of the procedure exposing both the patient as well as the operator to significant radiation dose. It is, therefore, essential to use adequate collimation tailored to the smallest required area.

\section{Right sided puncture (Figure 4)}

Fluoroscopic guidance is required for right sided percutaneous biliary access. After initial preparation, sponge forceps are placed at the intended site of skin entry which is usually below the 10th rib at mid-axillary line. Fluoroscopy is required to confirm its position over the liver parenchyma, below the costophrenic sulcus and away from adjacent bowel. Blind puncture is performed along the superior margin of rib to avoid injury to the intercostal neurovascular bundle, which runs along the inferior border of rib. After entry, the needle is directed cranially and parallel to the table into the liver parenchyma till a suitable duct is punctured, which can be reviewed using ultrasound.

\section{Left sided puncture}

Access to left sided biliary radical is obtained using ultrasound guidance for subxiphoid needle insertion.
After initial puncture, the needle is directed caudally and about 45 degrees medially to target segment 3 duct.

Irrespective of the side of puncture, it is essential to avoid puncturing central ducts as this increases the risk of injury to vascular structures as well as the technical difficulty in manipulation of catheters and guidewires. In case of inadvertent central puncture, it is better to reattempt targeting a peripheral bile duct without repeat capsular puncture.

Puncture may be technically challenging in non-dilated or minimally dilated biliary systems. Both fluoroscopic and ultrasound guidance have been used successfully to target the bile ducts by various authors., ${ }^{910}$ Additional supportive measures like use of in-dwelling T-tube for cholangiogram, CT guided puncture of bile duct and percutaneous placement of temporary drain in gall bladder have been suggested to facilitate the procedure. ${ }^{9}$

As percutaneous puncture of biliary system happens to be the most crucial step in the entire procedure, it is important to adequately secure the access once properly established. Additional anchorage may be used at the skin puncture site using vascular sheath to avoid the risk of losing access. It not only secures the biliary access but also allows multiple exchanges of catheters and guidewires without injuring the hepatic parenchymal tract. The sidearm provides an additional access for contrast injection without disturbing the position of catheter or guidewire. ${ }^{8}$
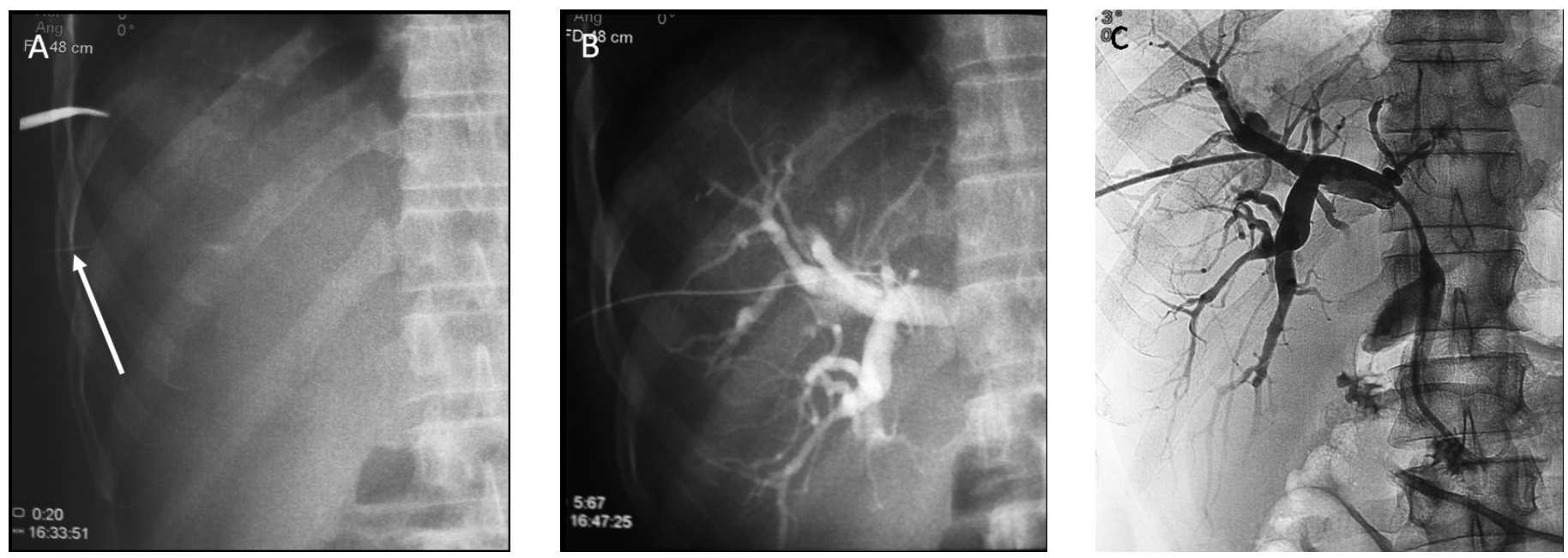

Figure 4: Right-sided puncture. (A): Using curved forceps to mark skin entry site below 10th rib at mid-axillary line under fluoroscopy. (B): Subsequent blind puncture and needle advancement in hepatic parenchyma directed cranially to target anterior sectoral duct which is confirmed by contrast injection. (C): Final check cholangiogram showing the position of internal-external drainage catheter. 
After the initial puncture, needle is advanced into liver parenchyma targeting appropriate biliary radical under ultrasound guidance. Once the actual target is reached, the inner stylet is removed and diluted nonionic iodinated contrast is injected gently while retracting the needle under fluoroscopy till biliary opacification is noted. The correct rate of contrast injection should just leave a thin linear trail of contrast along the needle tract.

\section{How to identify biliary opacification}

Early opacification of biliary radical can be identified on fluoroscopy. The contrast gradually moves away from the needle tip to outline a tubular structure as biliary radicals fill towards the hilum. However, in obstructed systems with gross upstream dilatation, the contrast may get diluted with swirling motion. Once a bile duct is identified, further needle retraction is stopped and contrast is injected slowly to outline the rest of the biliary tree.

It is absolutely essential to avoid overdistension of the biliary system in patients with cholangitis as this will inevitably lead to sepsis. Volume of injected contrast should be strictly limited to the minimum required to opacify the biliary system.

\section{Trouble during initial cholangiogram}

Obtaining a proper initial cholangiogram is an essential prerequisite as it serves as a roadmap for the subsequent navigation of multiple catheters and guidewires along the biliary channels. Hence it is important to be able to recognize the problems that may occur during initial cholangiogram including their implications and how to manage them.

\section{Rapid contrast dissipation}

Biliary radicals course in close proximity to hepatic artery and portal vein branches in portal triads. Hence while attempting to puncture the bile duct; there may be accidental injury to any of these vascular structures. Rapid dissipation of injected contrast suggests position of needle tipin a vascular structure- while the direction of flow is towards the periphery of liver in portal vein and hepatic artery branches, hepatic venous flow is directed cranially and centrally towards right atrium. Once identified, further needle advancement should be stopped followed by withdrawing and redirecting the needle tip in hepatic parenchyma.

\section{Persistent contrast stain}

If the contrast doesn't dissipate away from the needle tip, it suggests parenchymal opacification, which could either be due to dislodgement of needle or due to puncture of a small peripheral duct. Parenchymal extravasation when present needs to be identified early and avoided as large stagnant contrast blobs may obscure the biliary anatomy.

\section{Non-opacification of biliary radical in first attempt}

If the bile duct could not be punctured during the first needle passage, it basically calls for redirecting the needle in subsequent attempt. However, it is important to remember avoiding multiple punctures of the liver capsule as it increases the risk of bleeding.

While retracting the needle, halt before reaching the liver capsule. Any change of direction of needle tip has to be done within the liver parenchyma without puncturing the capsule again.

Sometimes, when the primary confluence is partially patent and contrast injected from one side opacifies the contralateral ductal system. In such situation, the contralateral contrast filled biliary system should not be left undrained as retained contrast in the biliary system may give rise to chemical cholangitis.

\section{Non-opacification of left-sided ducts}

In a right-sided puncture, this might indicate occlusion of primary confluence with separation of right and leftsided ductal system. However, anatomically left lobe of liver and its ducts are anterior and hence non-dependent compared to right lobe of liver in a supine patient. Hence, even if the confluence is patent, they might not opacify properly in a right sided puncture.

Gently rolling the patient to right anterior position might help in filling the ducts, but care should be taken to prevent needle dislodgement. 


\section{Extensive intraluminal filling defects}

Intraluminal filling defects on cholangiogram may signify calculi, blood clot, tumour or air bubble, the latter being discrete well defined filling defects which gets lodged in non-dependent radicals. Calculi also present as discrete filling defects, which may or may not be seen on plain films. Tumour, on the other hand, is seen as irregular mural nodule or stricture.

Blood clots are identified as serpiginous intraluminal filling defects. When extensive, it indicates hemobilia and requires temporary suspension of procedure. Patient'svitalsshould be monitored along with resuscitation as required. In most of the cases, bleeding responds to tamponade effect alongwith frequent flushing of catheter with normal saline to wash away the clots. However, if clots recur or bleeding continues, an urgent diagnostic angiogram of hepatic vessels may be required to find the source of bleeding (discussed later) (Figure 5).

Once access to biliary system is established, the next most important step is to negotiate the site of obstruction. Although, most people use $5^{\circ} \mathrm{F}$ angiographic catheters, negotiating hilar strictures may sometimes be difficult with straight tip catheters. There are specially designed biliary manipulation catheters (BMC) which may prove useful in such cases. They have a short stiff shaft with angled tip that achieves good directional and torque control over the guidewire enabling probing across acutely angle primary confluence or tight hilar strictures. In the absence of aforementioned, commonly used angled tip $5^{\circ} \mathrm{F}$ angiographic catheters like PICKARD can also be modified to serve the purpose (Figure 6).

While negotiating the lesion, probing should be gentle using the floppy end of straight tip hydrophilic guidewire. Use of stiff end or hard metallic guidewire is strictly contraindicated as this can perforate the bile duct causing hemorrhage and lead to false tract formation.

\section{When to anticipate trouble during catheter/ guidewire manipulation?}

\section{Difficulty in advancing catheter/guidewire}

Bile is a natural lubricant so manipulation of catheter and guidewire inside the biliary tree should be smooth. If
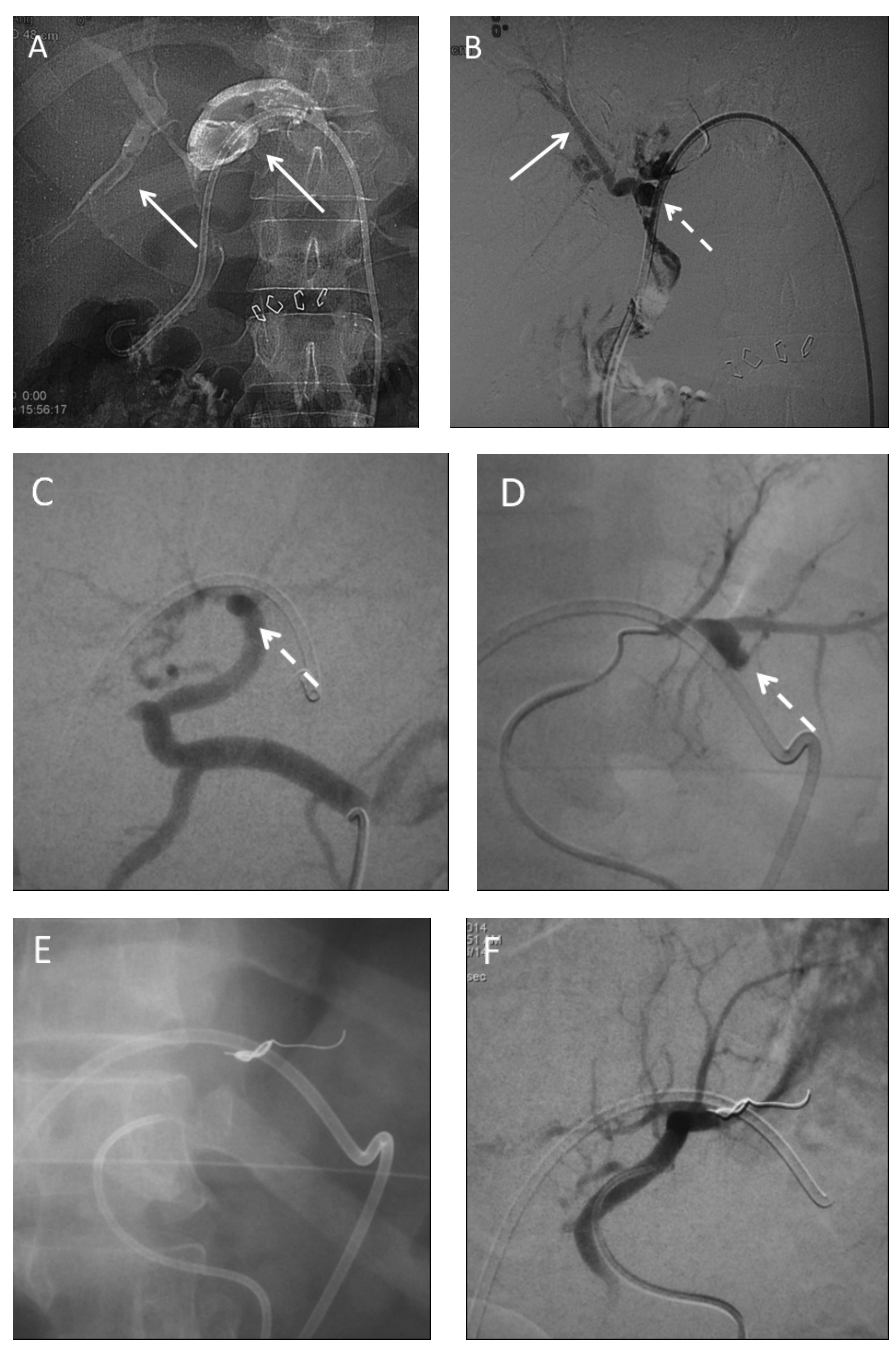

Figure 5: Bleeding from catheter (arterial source) (A): Cholangiogram through the drain revealed cast like filling defect distending left hepatic duct more than right hepatic ducts suggestive of blood clot (white arrows). (B): Digital subtraction (DS) cholangiogram revealed pseudoaneurysm arising from left hepatic artery along (dashed arrow) with opacification of branches of right hepatic artery (solid arrow) suggestive of presence of arterio-biliary fistula. (C): DS angiogram of common hepatic artery revealed pseudoaneurysm arising from proximal left hepatic artery which is better profiled in subsequent oblique view (D, dashed arrow). (E): Coil embolization of pseudoaneurysm proceeding distal to proximal to prevent backdoor filling from collateral circulation. (F): Check angiogram revealed complete embolization of the pseudoaneurysm. 

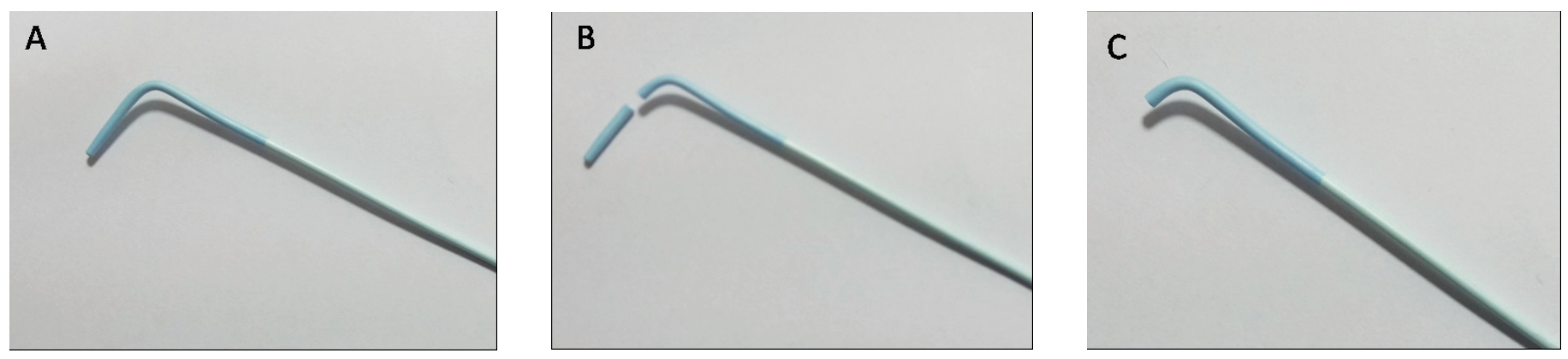

Figure 6: (A-C) Modifying 5F PICKARD catheter by cutting off part of its distal angled tip to have a shorter tip for better manipulation across hilar lesions as a substitute for biliary manipulation catheter.

one experiences difficulty in doing so, it usually suggests extra luminal position of catheter. Stop the procedure temporarily and confirm the intra-biliary location of catheter by aspiration of bile or injection of contrast.

\section{Unable to cross the lesion despite repeated attempts.}

Crossing the lesion may be difficult especially in tight strictures and grossly dilated biliary system. Overzealous attempts at crossing the lesion are to be avoided as this may increase the chances of bleeding. It is advisable to leave an external drainage using pigtail catheter for about two-three days to decompress the biliary system as well as to allow for resolution of edema. Decompression of marked biliary dilatation above the level of obstruction straightens out the course of the biliary channel, so that subsequent attempts of manipulation becomes easier. ${ }^{11}$

\section{Complications of PTBD}

Major complications to occur during the procedure or during follow up include hemorrhage, catheter dislodgement, bile leakage and infectious complications including cholangitis and sepsis. ${ }^{1}$ The individual complication and tips to manage them are addressed below.

\section{Bleeding from catheter (Figure 5): What to do?}

Bleeding complications are reported in 2-3\% of cases and can either manifest as bleeding through the percutaneous drain, which is the most common presentation, bleeding into perihepatic region or into gastrointestinal tract. ${ }^{12}$ The nature and quantity of bleeding characterizes the severity of vascular injury. While minor oozing from the skin entry site is usually due to skin bleed or bleeding from intercostal arteryor hepatic artery, bleeding from the drain can occur due to either venous injury (which is more common) or arterial injury. The authors present a flowchart below that offers as algorithmic approach to manage bleeding complications of PTBD (Figure 7).

\section{Pericatheter leakage : What to do?}

Pericatheter leakage of bile with soakage of dressing is a troublesome complication. Longstanding exposure to bile can lead to excoriation of surrounding skin. Catheter dislodgement or block or presence of ascites is usually the underlying causes. Catheter dislodgement is frequently encountered, especially in external drainage catheters, as their limited purchase in biliary system predisposes them to instability. To secure the catheter position in such cases, instead of positioning its tip immediately proximal to the site of obstruction, it can be maneuvered to a more peripheral right or left biliary radical, allowing a longer purchase of catheter in the biliary system (Figure 8). This in turn improves the catheter stability. ${ }^{11}$ The flowchart below suggests steps for addressing pericatheter bile leakage depending upon the cause (Figure 9).

\section{Sudden stoppage of drainage: What to do?}

Expected biliary output can range from 400 to $800 \mathrm{ml} /$ day. Sudden drop in catheter output implies either dislodgement or kinked catheter or blocked catheter, 
which is however, in situ. The flow chart below outlines the steps to evaluate for sudden stoppage of drainage catheter (Figure 10,11).

\section{Patient develops cholangitis: What to do?}

The reported rate of cholangitis postPTBD is highly variable, mostly caused by enteric bacteria. Multiple risk factors have been enumerated which include malignant or multiple ductal obstruction, prolonged catheter drainage, advanced patient age, calculi etc. ${ }^{13}$

As a remedial measure, appropriate antibiotic coverage is recommended to be institutedprior to PTBD, the duration of which may vary depending upon the patient's clinical status. ${ }^{1}$

Acute suppurative cholangitis is also an indication to go for two-stage delayed internal drainage (apart from grossly dilated biliary system) as it minimizes hardwire manipulations in an already contaminated biliary system reducing the morbidity of the procedure. ${ }^{11}$ Since, incomplete biliary drainage is the most important cause of ascending cholangitis, care should be taken to identify all the biliary radicals before undertaking the drainage procedure to so that no obstructed segment is left undrained, especially in multiple ductal obstruction. As transpapillary passage of catheter may be contributory to ascending cholangitis, external drainage with fluid and bile salt replacement is recommended in these patients. ${ }^{13}$

Delayed post-procedural cholangitis usually occurs when a trial of 'clamping' is offered after the conversion of external to internal-external biliary drainage using ring biliary catheter to allow the bile to drain into duodenum. The catheter should be promptly unclamped with establishment of external drainage, as most of this cholangitisare due to inadequate drainage of bile through the catheter. Although this measure can provide temporary relief, a more definitive solution is to upgrade to a higher caliber catheter (10 or $12 \mathrm{Fr}$ ) to allow better drainage.

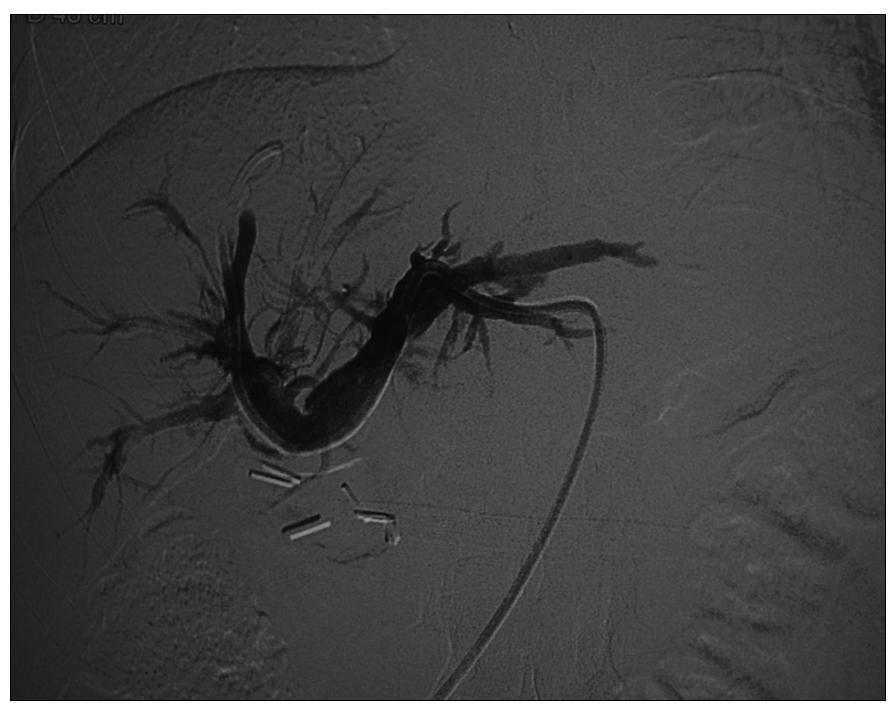

Figure 8: Cholangiogram showing left-to-right placement of external drainage catheter in a patient with HJ anastomotic stricture . Peripheral placement of tip of catheter into the contralateral side biliary tree allows longer purchase of catheter intp the biliary system preventing potential dislodgement.

Some even prefer supra-sphincteric placement of catheter tip as this retains the normal physiologic function of 
sphincter reducing duodenal reflux and chances of ascending cholangitis. ${ }^{11}$

\section{Biliary Stenting}

Once the site of occlusion has been traversed, the aim is to restorebiliary drainage internally into the gastrointestinal tract to minimize the loss of bile salts and electrolytes. There is an ongoing debate regarding the best mode of internal drainage between primary stentingas a one-step procedure or initial catheter drainage followed by secondary stenting, with the final decision resting upon the intervention radiologists' discretion, morphologic characteristics of biliary obstruction (primary stenting preferred in Bismuth type I and II strictures) and general condition of the patient. ${ }^{14}$ Available literature now favors primary stenting as it is convenient and safer, involving shorter duration of hospital stay and hence, more cost-effective for the patient. By obviatinga temporary biliary drainage catheter, the expected catheter related complications including undesirable lifestyle impairments are excluded as well. ${ }^{15,16,17}$

However, the authors, in their experience believe thatthere are certain clinical scenarios wherein catheter drainage may prove beneficial over primary stentingin selected cases due to the risk of early stent occlusion, namely:

1. Multi-segmental strictures with isolated segments and cholangitis.

2. If significant haemobilia occurs during the course of the procedure.

3. Coexistent stone disease.

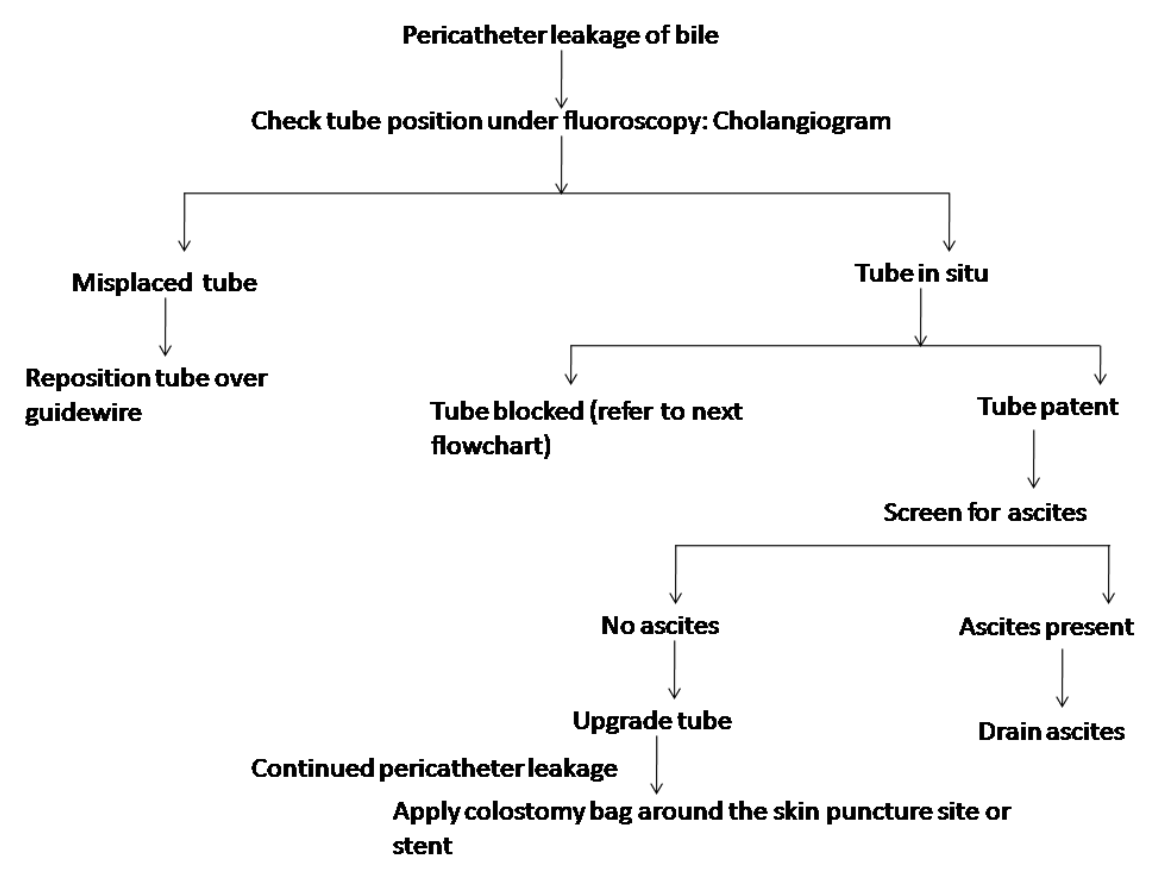

Figure 9: Algorithm for management of pericatheter bile leakage.

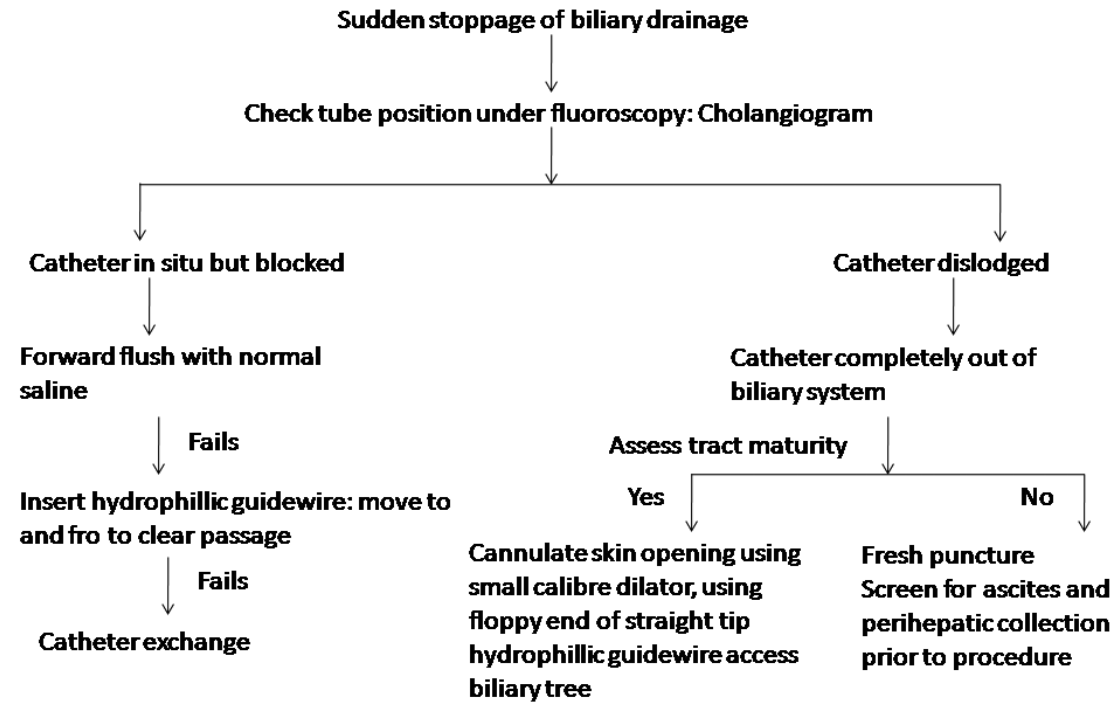

Figure 10: Algorithm for management of sudden stoppage of biliary drainage.

\section{Single or multiple stents? Unilateral or bilateral drainage?}

There is conflicting evidence as to suggest whether unilateral or bilateral stents should be placed. Published evidence suggests that although stent patency rate is better with bilateral drainage, there is no significant 

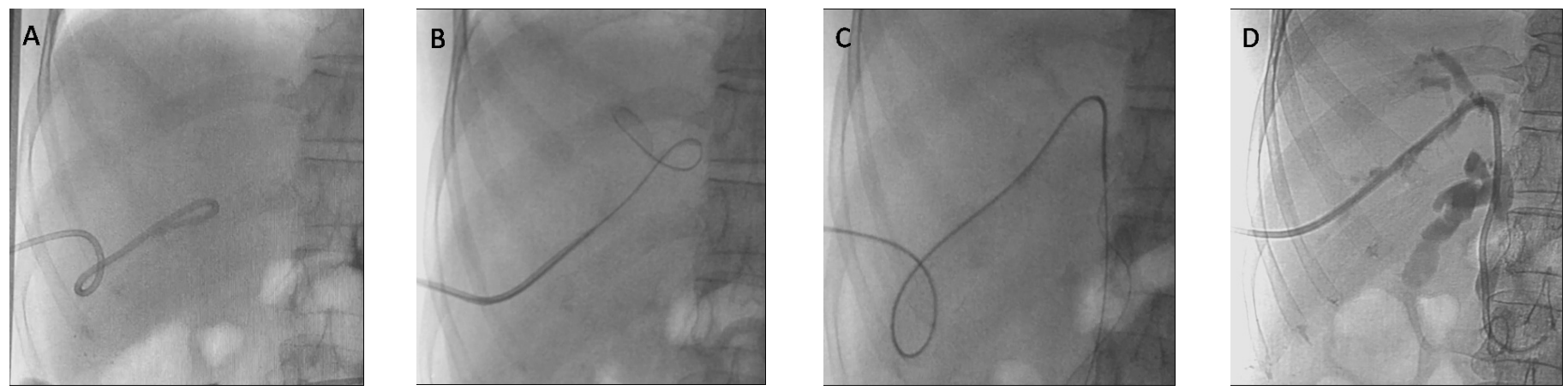

Figure 11: Dislodged catheter: Patient presented with absent drain output with soiling of dressing a week after PTBD. (A): Spot fluoroscopic image showing dislodged right sided external drainage catheter (B): Using floppy end of straight tip hydrophillic guidewire, the tract was probed to regain access into the biliary tree. (C): Once guidewire entered the biliary tree, drainage catheter was exchanged over guidewire with $5 \mathrm{~F}$ angiographic catheter for further manipulation. (D): Cholangiogram showing final position of internal-external drainage catheter.

difference between the two in terms of technical success rate, complications or patient survival. ${ }^{18,19}$

It is hypothesized that a single stent may suffice in Bismuth type I, II and III strictures, but multi-segmental occlusions, with complex proximal strictures (Bismuth type IV) would require placement of multiple stentsto prevent cholangitis of undrained segments and to achieve adequate relief of cholestasis to initiate chemotherapy. ${ }^{20-23}$ But, in the absence of sufficient prospective data or randomized controlled trials, efficacy of one over the other cannot be established unequivocally for palliative intent.

Several techniques of multiple stent placement have been described, chiefly stent-in-stent (in T-shaped or Y-shaped configuration, criss-cross configuration for tri-segmental drainage) (Figure 12,13) or side-by-side technique ${ }^{21,23-29}$ (Figure 14) and side-to-end technique. ${ }^{30}$ Table 4 summarizes the features, advantages and disadvantages of these techniques.

\section{Plastic or metallic stents?}

Both plastic and metallic stents are available, although the latter are preferably used in patients with malignant biliary obstruction in view of their prolonged patency rates ${ }^{18}$ apart from technical advantages like greater flexibility and minimal foreshortening at deployment. ${ }^{20}$ Uncovered self-expanding metallic stents have shown good results in palliation of jaundice with reduced need for intervention and delayed stent occlusion. ${ }^{33}$
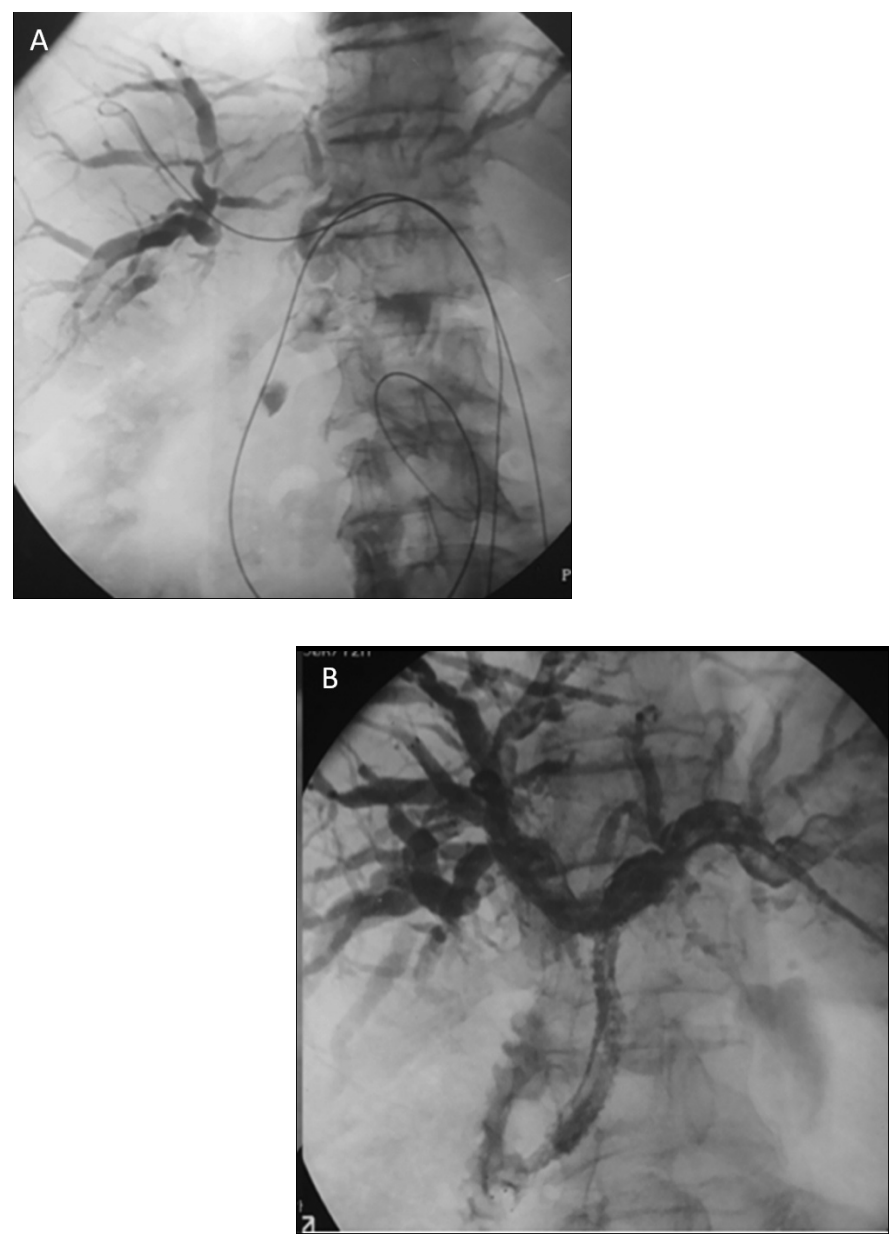

Figure 12: ( $A$ and $B)$ : $T$ shaped stent in hilar cholangiocarcinoma. Using left sided access, first stent was placed from left hepatic duct to right hepatic duct, and the second stent was deployed through the mesh of the first stent from left hepatic duct into common bile duct. 
Plastic stents, on the other hand, have limited role in long term palliation of malignant biliary obstruction due to early occlusion. They are most frequently used these days by endoscopists after sphincterotomy or as a temporary measure for biliary drainage till definitive surgery take places. But even in latter instance, internalexternal drainage via PTBD is considered a better option.

\section{Role of Covered Metallic Stents for Malignant Biliary Strictures}

Covered metallic stents theoretically minimize tumour ingrowth thereby reducing chances of stent blockage. However, occlusion of side branches while stenting hilar lesions, occlusion of cystic duct and MPD leading to cholecystitis and pancreatitis, respectively and stent migration are reported complications, seen more often as compared to bare stents with comparable outcomes. ${ }^{21}$

\section{Appropriate Position of Stent}

Certain technical points should be kept in mind during deployment of biliary stents for their adequate functioning. As a rule, strictures are usually overstented with a safety margin of about $2 \mathrm{~cm}$ at both proximal and distal ends of occlusion, to prevent tumour overgrowth at stent margins. ${ }^{34,35}$

Metallic stents undergo foreshortening during the course of their deployment along with a tendency of forward migration. Hence, the need to "balance" the position of stent leaving equal lengths both proximal and distal to tumour as this will prevent slippage of stent immediately after deployment. If post-stent deploymentcholangiogram reveals persistent waist at the site of stricture, balloon dilatation of the stent can be performed in the same setting. ${ }^{36}$

In addition, depending upon the level of occlusion and the anatomy of extrahepatic bile duct, percutaneous metallic stents can either be positioned above the ampulla of Vater (suprapapillary method) or across it (transpapillary method) ${ }^{37,38}$ each technique with its own merits and drawbacks (Figure 15). Table 5 summarizes the differences between the two methods. Since stent occlusion, whether early or delayed, is an anticipated
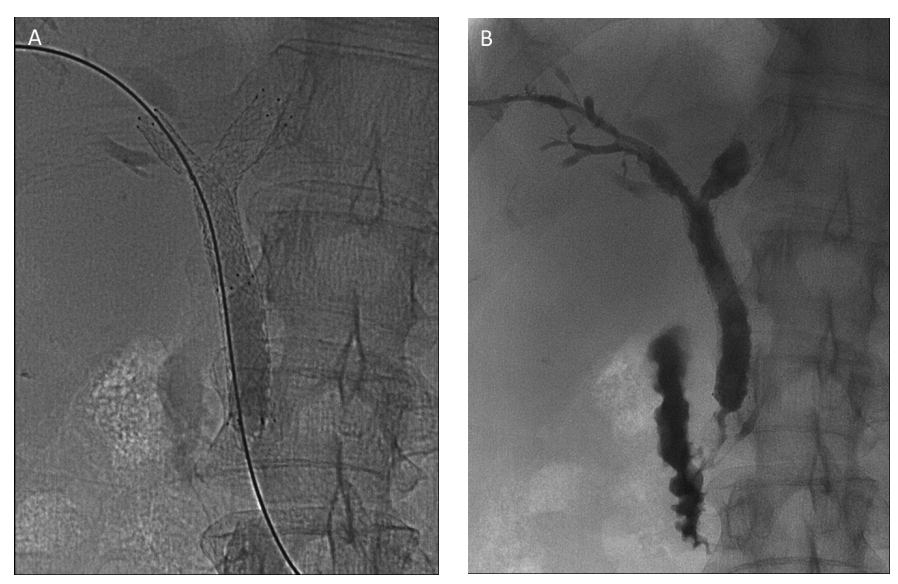

Figure 13: (A and B): $Y$ shaped stent. Using bilateral access, first stent was placed from left hepatic duct into common bile duct and the second stent was deployed from right hepatic duct into common bile duct through the mesh of first stent.

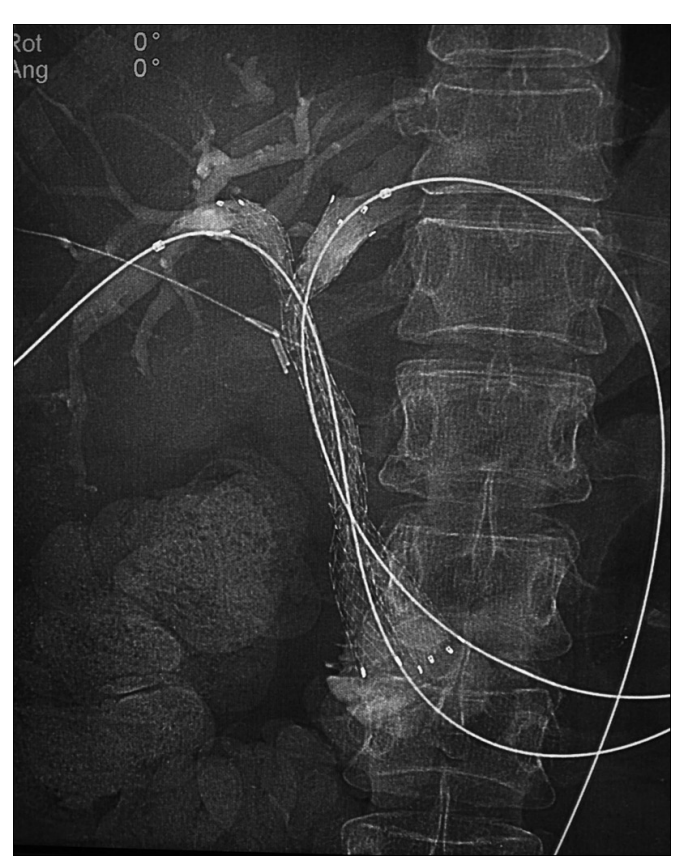

Figure 14: Side-by-side stent. Using bilateral access, two parallel stents are placed side-by-side in common bile duct.

complication, percutaneous stents should be deployed in such a position so that in case of subsequent occlusion, they are amenable to percutaneous catheterization. ${ }^{40}$

When bilobar stents are deployed, it is recommended that their distal ends be positioned at the same level in common bile duct to enable endoscopic retrograde cannulation for any re-intervention, if required. ${ }^{21}$ 
Table 4: Comparison of techniques of multiple biliary stent placement

\begin{tabular}{|c|c|c|c|}
\hline Features & Side-by-side ${ }^{22}$ & Stent-in-stent ${ }^{25,30}$ & Side-to-end ${ }^{29,19}$ \\
\hline $\begin{array}{l}\text { Number of percutaneous } \\
\text { access }\end{array}$ & Bilateral & $\begin{array}{l}\text { Unilateral (T configuration, } \\
\text { obtuse angle between RHD } \\
\text { and LHD) } \\
\text { Bilateral (Y configuration, } \\
\text { acute angle between RHD and } \\
\text { LHD) } \\
\text { Two unilateral or bilateral } \\
\text { (criss-cross configuration, } \\
\text { RASD separated from } \\
\text { RPSD) }\end{array}$ & Unilateral or bilateral \\
\hline Placement of stent & Parallel configuration & $\begin{array}{l}\text { Second stent inserted via mesh } \\
\text { of first stent into CBD }\end{array}$ & $\begin{array}{l}\text { Second stent inserted } \\
\text { overlapping with proximal } \\
\text { edge of first stent }\end{array}$ \\
\hline Advantage & Technically simple & $\begin{array}{l}\text { Uniform dilatation of entire } \\
\text { stricture within single stent } \\
\text { caliber } \\
\text { Overlapping stent prevent } \\
\text { displacement } \\
\end{array}$ & $\begin{array}{l}\text { No manipulation through mesh } \\
\text { of first stent. }\end{array}$ \\
\hline Disadvantages & $\begin{array}{l}\text { Bilateral skin puncture, Over- } \\
\text { distention of CBD } \\
\text { Inadequate stent expansion at } \\
\text { hilum. }{ }^{24,30}\end{array}$ & $\begin{array}{l}\text { Technically difficult to } \\
\text { negotiate with closed-cell } \\
\text { design of first stent } \\
\text { Crushing of first stent during } \\
\text { deployment of second stent }\end{array}$ & $\begin{array}{l}\text { In unilateral access, dilatation } \\
\text { of percutaneous route to } \\
\text { accommodate parallel two- } \\
\text { stent delivery system. } \\
\text { No stent overlap-risk of stent } \\
\text { separation. }\end{array}$ \\
\hline
\end{tabular}

\section{Pre-stent balloon dilatation of malignant}

\section{stricture?}

Usually pre-stent dilatation of malignant biliary stricture is not required as this may cause tumoral bleed leading to early blockage of stent. ${ }^{16}$

\section{Follow up after biliary stenting}

Protocol for follow up after biliary stenting essentially involves clinical evaluation, laboratory investigation and ultrasound every three months. In case of stent blockage, patient needs to report to the interventional suite for check cholangiogram. ${ }^{41}$

\section{Stent Block: What to do?}

Stent occlusion usually results from biliary sludge encrustation, tumour ingrowth through the interstices of the mesh or tumour overgrowth at the ends of the stent. ${ }^{40,42}$
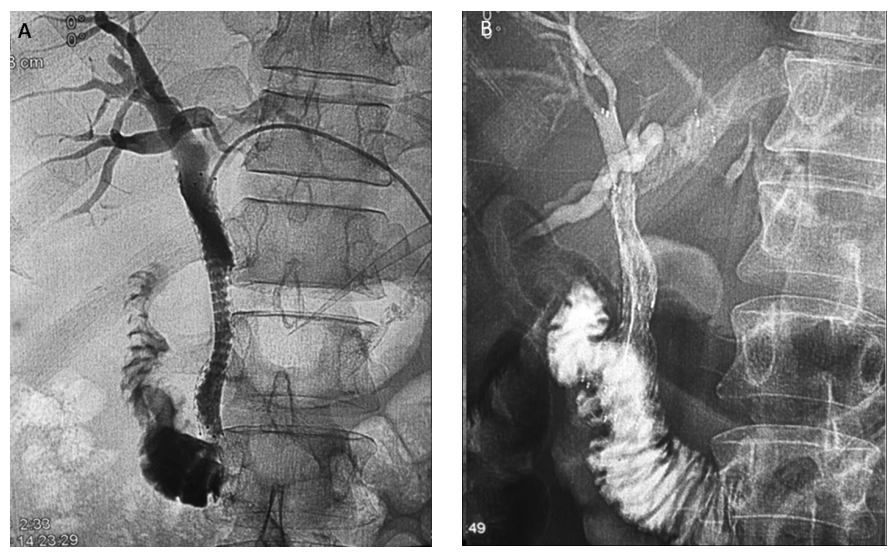

Figure 15: Cholangiogram showing suprapaillary (A): and transpapillary (B): placement of stent in common bile duct.

Patients usually present with increasing jaundice, cholangitis and peri-catheter soakage of bile around a clamped temporary "access" catheter, if left in situ. 
Table 5: Comparison of suprapapillary and transpapillary method of stent placement

\begin{tabular}{|c|c|c|}
\hline Characteristic & Suprapapillary & Transpapillary \\
\hline Level of occlusion & $\begin{array}{l}\text { Proximal or mid CBD occlusion } \\
\text { Bile duct angulation away from stricture. }\end{array}$ & $\begin{array}{l}\text { Distal CBD occlusion } \\
\text { Bile duct angulation below the stricture }\end{array}$ \\
\hline Cause of stent blockage & Tumour in-or overgrowth & Sludge incrustation \\
\hline Risk of pancreatitis & - & + \\
\hline Other complications & $\begin{array}{l}\text { Exaggeration of distal CBD angulation if } \\
\text { close to the end of stents leading to poor } \\
\text { drainage }\end{array}$ & $\begin{array}{l}\text { Duodenal ulceration/bleeding/perforation } \\
\text { Reflux of duodenal contents into bile duct }\end{array}$ \\
\hline $\begin{array}{l}\text { Stent patency } \\
\text { Cumulative rate at } 6 \text { and } 12 \text { months } \\
\text { Mean duration }\end{array}$ & $\begin{array}{l}66 \% \text { and } 29 \% \text {, respectively } \\
262 \pm 22 \text { days }\end{array}$ & $\begin{array}{l}64 \% \text { and } 39 \% \text {, respectively } \\
290 \pm 27 \text { days }\end{array}$ \\
\hline
\end{tabular}

In such cases, it is recommended to put an external drainage catheter proximal to the obstruction to relieve the upstream biliary dilatation (Figure 16). A few days later, as the acute infection and biliary dilatation subsides, internalization may be attempted which if possible is followed by insertion of either an additional co-axial selfexpanding metallic stent (if safe landing zone is available) or ring biliary catheter ${ }^{43}$ (Figure 17).

For stent occlusion in proximal bile duct tumours, placement of internal-external drainage catheter offers better palliation than inserting a new metallic stent due to limited life expectancy of this group of patients. ${ }^{40}$

\section{Benign biliary stricture}

Benign biliary strictures are commonly seen in clinical practice as a complication of cholecystectomy (especially laparoscopic $)^{44}$ due to bile duct injury, anastomotic strictures after liver transplant, and common bile duct stricturesas sequelae to chronic pancreatitis, inflammatory pathologies like primary sclerosing cholangitis and recurrent pyogenic cholangitis. ${ }^{45}$

Endoscopic retrograde route is the preferred technique due to its ease, repeatability and greater patient comfort. ${ }^{45}$ Surgical revision is technically challenging in these cases due to very small length of bile duct stump available for more proximal anastomosis and higher chances of recurrence. Percutaneous approach is reserved for cases of failed endoscopic approach or when it is precluded in cases with altered surgical anatomy eg. Roux-en-Y hepaticojejunostomy (HJ) or

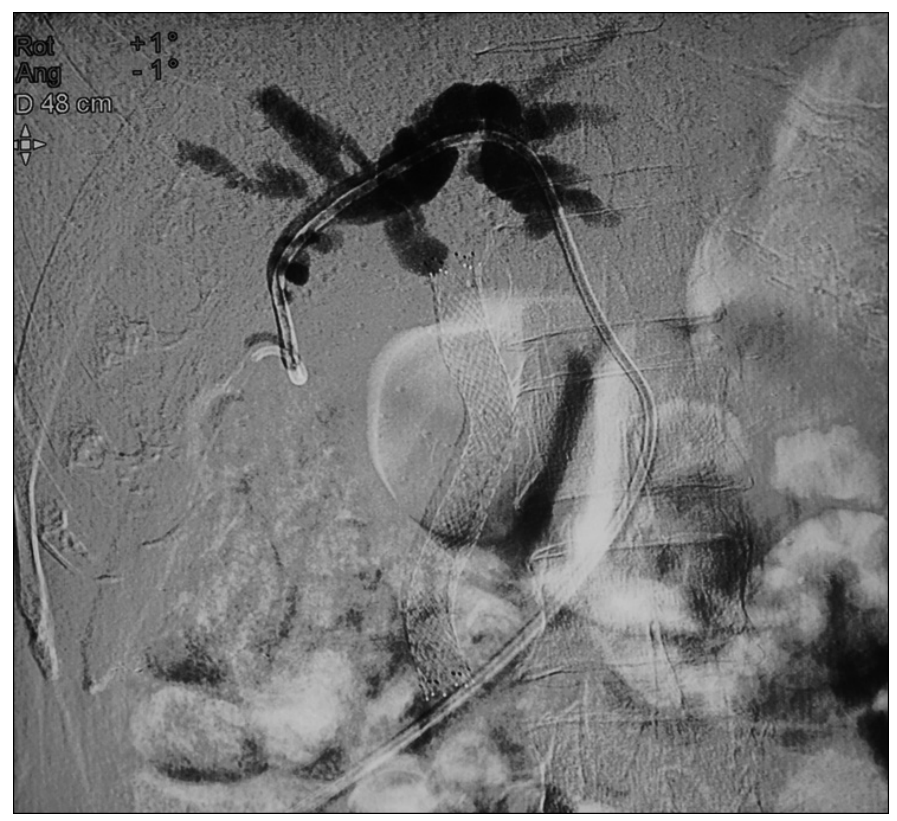

Figure 16: Stent Block . Cholangiogram revealed dilated bilobar intrahepatic biliary radicals with no passage of contrast across the stent into duodenum. An external drainage catheter was left proximal to obstruction with its tip into the contralateral side biliary system for temporary relief of cholestasis.

choledochojejunostomy. Benign biliary strictures are notorious torecur; hence their satisfactory treatment requires repeated sessions of dilatation. ${ }^{46}$ Moreover, long standing low grade obstruction as seen in these cases with supervening infection decreases the pliability of liver parenchyma, making dilatation of these strictures particularly challenging. ${ }^{46}$ 
The basic steps of PTBD remain the same as described earlier, however there are few technical challenges which include,

1. Accessing the duct, since the biliary system is minimally dilated

2. Increased stiffness of hepatic parenchyma due to long standing cholestasis making manipulation of catheters and guidewires difficult.

3. Identification of the site of stricture.

Tips to overcome these challenges:

1. For accessing minimally dilated system, use of micro puncture set or Neff set rather than $18 \mathrm{G}$ needle

2. If manipulation of catheters/dilatators is difficult, due to stiff liver parenchyma, one may place external drainage tube for a week and then re-attempt to cross the stricture.

3. HJ site to be identified by

- looking at the site of contrast trickle into the jejunal loop, or

- $\quad$ surgical staples left over at the HJ site help in identifying the stricture site.

Once, the stricture is negotiated, dilatation of the stricture is done using a balloon catheter of either $10 \mathrm{~mm}$ or $12 \mathrm{~mm}$ diameter, followed by placement of $10-12^{\circ} \mathrm{F}$ catheter across the anastomotic site. This catheter is kept for atleast 8-12 weeks, after which check cholangiogram is done, to look for free flow of contrast across the anastomotic site into bowel. If there is any residual narrowing, repeat dilatation is done and a larger bore catheter $\left(14-16^{\circ} \mathrm{F}\right)$ is placed across the anastomotic site. This catheter may be kept for a variable period ranging from 6 to 12 months followed by two weeks' trial of capping done by keeping the catheter tip proximal to the anastomotic site. If well-tolerated and subsequent check cholangiogram confirms free flow of contrast, the catheter is removed. The duration of the treatment regimen has a widely variable range in the reported series from 1.1 to 19.9 months $^{47,48}$ (Figure 18). This structured protocol has showed patency rates of $84 \%$ at 1 year and $74 \%$ at 5 year, comparable to other studies with significantly shorter duration of treatment. ${ }^{49}$

However, repeated sessions of balloon dilatation of strictures are extremely painful for the patient. Similarly, long-term percutaneous transhepatic large bore biliary
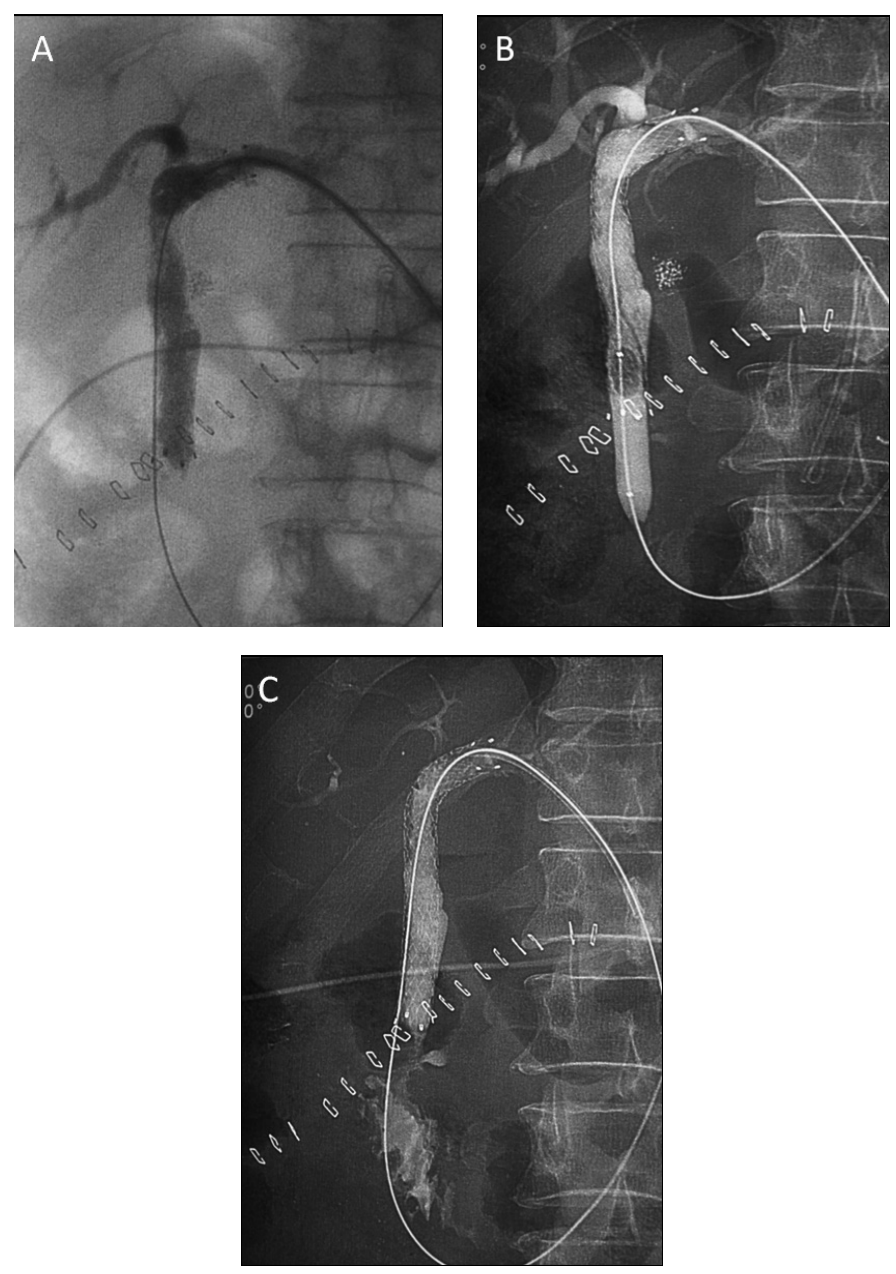

Figure 17: Stent block due to sludge encrustation in another patient: (A): Cholangiogram through vascular access sheath revealed mild dilatation of bilateral intrahepatic biliary radicals and common bile duct (CBD) with obstruction at lower end of CBD. No distal passage of contrast into duodenum was seen (B): Securing access across the stent into duodenum, over the wire balloon was inflated at lower end of CBD and the passage was cleared off debris by manipulating the balloon to and fro. (C): Final cholangiogram showed free passage of contrast into duodenum.

drainage catheters are also inconvenient and painful for the patient. To address these problems, fully covered, removable metallic stents have been introduced for benign biliary strictures with promising results. ${ }^{50,51}$ In addition to the percutaneous transhepatic route, indwelling $\mathrm{T}$ tube as well as the afferent or efferent limb of Roux-en-Y loop, which is usually surgically fixed to anterior abdominal wall can also be used to access the biliary tree. 

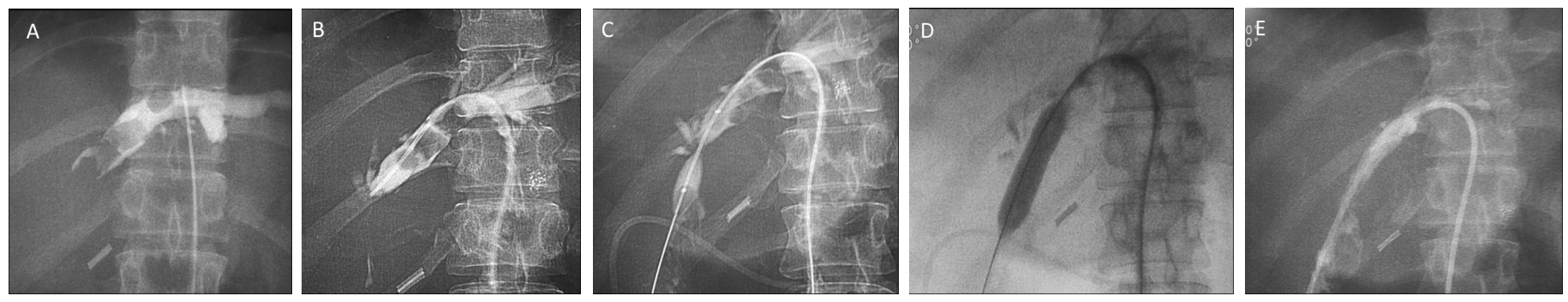

Figure 18: Dilatation of HJ stricture with stone removal. (A,B): Initial cholaniogram after puncture revealed dilated left hepatic duct with abrupt cut-off at the expected anastomotic site. No distal passage of contrast into bowel loops seen . In addition, multiple rounded filling defects seen in left hepatic duct suggestive of calculi. (C,D): Balloon inflation across the anastomotic stricture site. Care must be taken to obliterate the waist completely at the stricture site. After stricture dilatation, the inflated balloon was swiped forward along the hepatic duct repeatedly to clear the stones across the anastomotic site into bowel. (E): Final cholangiogram showed free passage of contrast into jejunum with absence of any intrabiliary filling defects.

\section{PTBD in bile leak (Figure 19)}

Iatrogenic bile duct injury may also present as biliary leak either into peritoneal cavity or as biliary-cutaneous fistula especially in the immediate post-operative period.Biliary diversion in the form of PTBD has been shown to have very good efficacy in the non-operative management of these patients. By draining the bile away from the site of defect, it reduces inflammation and promotes healing. ${ }^{52,53}$ Since the biliary channels are non-dilated, gaining percutaneous access is the main challenge.

\section{Tips to access minimally dilated biliary system}

Use of Micropuncture set or Neff mini-access set is advisable to puncture the biliary radicles. The puncture of the biliary ducts is performed under fluoroscopic and/or ultrasonographic guidance along the mid axillary line on right side. The entry site should be one intercostal space above the inferior border of right lobe of liver along the superior margin of the rib to avoid pleural transgression. Since these patients have nondilated intrahepatic bile ducts, an initial puncture is performed close to the hilum where the ducts are slightly larger incaliber, followed by injection of a small amount of diluted iodinated contrast to opacify the biliary tree which subsequently helps in puncturing a peripheral duct under fluoroscopic guidance. Thereafter, a 0.018 inch guide wire is advanced into the biliary system and later substituted by a conventional 0.035 inch stiff guidewire. Finally, an 8-Fr external biliary drainage catheter is inserted keeping the side-holes proximal to the site of leakto allow healing. Apart from catheter drainage, fully covered retrievable metallic stents have also been used successfully to seal free bile leaks. ${ }^{54}$

\section{Percutaneous biliary intervention in post liver transplant recipients}

Biliary complications are commonly encountered after liver transplantation and can occur either in the immediate post-transplant period or as a delayed complication. Biliary complication can present as bile leak or stricture, usually at the anastomotic site. Endoscopic route is preferred in this sub-group of patients in view of its safety and reduced morbidity while percutaneous route is reserved for failed endoscopic approach or in cases with Roux-en-Y reconstruction. A technique that combines both the approaches i.e percutaneous transhepatic access to the biliary tree followed by endoscopic retrograde route for stent placement has been described, also known as "rendezvous'technique. ${ }^{55,56}$ This technique has been shown to have good results in patients with angulated or twisted biliary strictures for replacement of PTBD catheters with inside stents in biliary strictures after living donor liver transplantation. ${ }^{57}$ The classical 'rendezvous' technique used percutaneously inserted guidewire for endoscopic approach to the bile tree while subsequently, multiple modifications of the technique have been suggested including Kumpe catheter instead of guidewire with promising results. ${ }^{58}$ Surgery remains the 

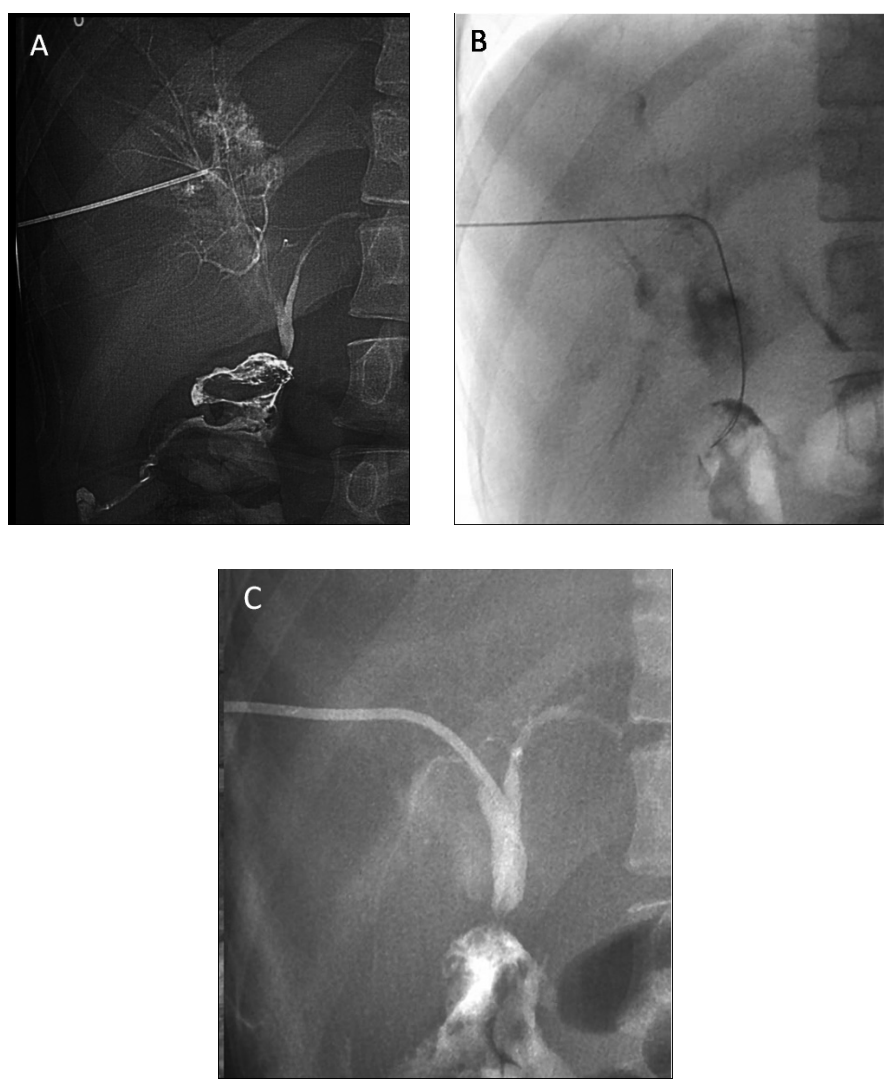

Figure 19: Post-operative bile leak. Patient presented post-operatively with fever, rising serum bilirubin and total leukocyte count and pain in right upper quadrant of abdomen. (A): Initial cholangiogram after puncture revealed minimal intrahepatic biliary radical dilatation with abrupt narrowing at the choledochojejunostomy site. Contrast was seen trailing along right subhepatic space signifying peritoneal leakage of bile (white arrow). Biliary leaks usually present with minimal or no biliary radical dilatation despite raised serum bilirubin as bile drains into low pressure peritoneal cavity or outside into the collection bag if there is a drain in situ. (B): Subsequent access into biliary tree was gained using guidewire manipulation (C): Cholangiogram showing final position of external drainage catheter for biliary diversion.

last resort to salvage the graft when multiple endoscopic and percutaneous attempts fail.

In conclusion, percutaneous access to biliary tree offers a relatively atraumatic and non-surgical alternative to manage a wide range of benign and malignant etiologies of biliary obstruction. As experience with these techniques grows, various technical roadblocks that are encountered during the procedure get reportedalongwith specific maneuvers to manage them. Although, not exhaustive, this review aims to add our experience to the existing literature regarding some of those key technical aspects hoping that it contributes to the better performance of these procedures.

\section{References}

1. Saad WE, Wallace MJ, Wojak JC, Kundu S, Cardella JF. Quality improvement guidelines for percutaneous transhepatic cholangiography, biliary drainage, and percutaneous cholecystostomy. $J$ VascInterv Radiol. 2010;21(6):789-95.

2. Kutup A, Yekebas EF, Izbicki JR. Management postoperativer Pankreaskomplikationen. Chir Gastroenterol. 2008; 24:108-114.

3. Sohn TA, Yeo CJ, Cameron JL, et al. Pancreaticoduodenectomy: role of interventional radiologists in managing patients and complications. J Gastrointest Surg. 2003;7:209-219.

4. Funaki B. Percutaneous Biliary Drainage. Seminars in Interventional Radiology. 2007;24(2):268-271.

5. Sherman S. Endoscopic drainage of malignant hilar obstruction: is one biliary stent enough or should we work to place two? Gastrointest Endosc. 2001;53:681-4.

6. Patel IJ, Davidson JC, Nikolic B, Salazar GM, et al ; Standards of Practice Committee, with Cardiovascular and Interventional Radiological Society of Europe (CIRSE) Endorsement. Consensus Guidelines for Periprocedural Management of Coagulation Status and Hemostasis Risk in Percutaneous Image-guided Interventions. $J$ Vasc and Interv Radiol. 2012;23;727-736.

7. Gazelle GS, Lee MJ, Mueller PR. Cholangiographic segmental anatomy of liver. Radiographics. 1994;14(5):1005-13.

8. Gwon DI, Laasch HU. Radiological approach to benign biliary strictures. Gastrointest Interv. 2015;4:9-14.

9. Kühn JP, Busemann A, Lerch MM, Heidecke CD, Hosten N, Puls R. Percutaneous biliary drainage in patients with nondilated intrahepatic bile ducts compared with patients with dilated intrahepatic bile ducts. Am J Roentgenol. 2010;195(4):851-7.

10. Hayashi N, Sakai T, Kitagawa M, et al. US-guided left sided biliary drainage: nine-year experience. Radiology. 1997;204:119-122.

11. Mueller PR, van Sonnenberg E, Ferrucci JT Jr. Percutaneous 
biliary drainage: technical and catheter-related problems in 200 procedures. Am J Roentgenol. 1982;138(1):17-23.

12. Saad WE, Davies MG, Darcy MD.Management of bleeding after percutaneous transhepatic cholangiography or transhepatic biliary drain placement. Tech Vasc Interv Radiol. 2008;11(1):60-71.

13. Clouse ME, Evans D, Costello P, Alday M, Edwards SA, McDermott WV. Percutaneous transhepatic biliary drainage.Complications due to multiple duct obstructions. Annals of Surgery. 1983;198(1):25-29.

14. Gandini R, Fabiano S, Pipitone V, et al. Management of biliary neoplastic obstruction with two different metallic stents implanted in one session. Cardiovasc Intervent Radiol. 2005;28:48-52.

15. Chatzis N, Pfiffner R, Glenck M, Stolzmann P, Pfammatter T, Sharma P. Comparing percutaneous primary and secondary biliary stenting for malignant biliary obstruction: A retrospective clinical analysis. The Indian Journal of Radiology \& Imaging. 2013;23(1):38-45.

16. Inal M, Aksungur E, Akgül E, Oguz M, Seydaoglu G. Percutaneous placement of metallic stents in malignant biliary obstruction: One-stage or two-stage procedure? Predilate or not? Cardiovasc Intervent Radiol. 2003;26:40-5.

17. Thornton RH, Frank BS, Covey AM, et al. Catheter-free survival after primary percutaneous stenting of malignant bile duct obstruction. Am J Roentgenol. 2011;197(3): W514-8.

18. Hong W, Sun X, Zhu Q. Endoscopic stenting for malignant hilar biliary obstruction: should it be metal or plastic and unilateral or bilateral? Eur J Gastroenterol Hepatol. 2013;25(9):1105-12.

19. Li M, Wu W, Yin Z, Han G. Unilateral versus bilateral biliary drainage for malignant hilar obstruction: a systematic review and meta-analysis [Article in Chinese]. Zhonghua Gan Zang Bing Za Zhi. 2015;23(2):118-23.

20. Sato Y, Inaba Y, Hara K, et al. Multiple metallic stents placement for malignant hilar biliary obstruction: Perspective of a radiologist. Gastrointestinal Intervention. 2016;5:52-59.

21. vanDelden OM, Laméris JS. Percutaneous drainage and stenting for palliation of malignant bile duct obstruction. Eur Radiol. 2008;18:448-56.

22. Rerknimitr R, Angsuwatcharakon P, Ratanachu-Ek $\mathrm{T}$, et al. Asia-Pacific consensus recommendations for endoscopic and interventional management of hilar cholangiocarcinoma. $J$ Gastroenterol Hepatol. 2013;28:593-607.
23. Inal M, Akgül E, Aksungur E, Seydaoğlu G. Percutaneous placement of biliary metallic stents in patients with malignant hilar obstruction: unilobar versus bilobar drainage. J VascInterv Radiol. 2003;14:1409-16.

24. Kim CW, Park AW, Won JW, Kim S, Lee JW, Lee SH. T-configured dual stent placement in malignant biliary hilar duct obstructions with a newly designed stent. J VascInterv Radiol. 2004;15:713-7.

25. Gwon DI, Ko GY, Sung KB, et al. Percutaneous biliary metallic stent placement in patients with unilobar portal vein occlusion caused by advanced hilar malignancy: outcome of unilateral versus bilateral stenting. Am J Roentgenol. 2011;197:795-801.

26. Gwon DI, Ko GY, Kim JH, et al. Percutaneous bilateral metallic stent placement using a stent-in-stent deployment technique in patients with malignant hilar biliary obstruction. Am J Roentgenol. 2013;200:909-14.

27. Gwon DI, Ko GY, Yoon HK, et al. Safety and efficacy of percutaneous Y-configured covered stent placement for malignant hilar biliary obstruction: a prospective, pilot study. J VascInterv Radiol. 2012;23:528-34.

28. Gwon DI, Ko GY, Yoon HK, et al. Prospective evaluation of a newly designed T-configured stent graft system for palliative treatment of advanced hilar malignant biliary obstructions. J VascInterv Radiol. 2010;21:1410-8.

29. Bae JI, Park AW, Choi SJ, et al. Crisscross-configured dual stent placement for trisectoral drainage in patients with advanced biliary hilar malignancies. J VascInterv Radiol. 2008;19:1614-9.

30. Saito H, Hokotate H, Takeuchi S. Interventional therapy using percutaneous transhepatic route for biliary diseases. Nichidoku-Iho. 2007;52:41-53. [In Japanese, English abstract].

31. Ahn SJ, Bae JI, Han TS, et al. Percutaneous biliary drainage using open cell stents for malignant biliary hilar obstruction. Korean J Radiol. 2012;13:795-802.

32. Kubota Y, Nakatani S, Nakahashi Y, Takaoka M, Kin $\mathrm{H}$, Inoue $\mathrm{K}$. Bilateral internal biliary drainage of hilar cholangiocarcinoma with modified Gianturco Z stents inserted via a single percutaneous tract. $J$ Vasc Interv Radiol. 1993;4:605-10.

33. Lee TH, Moon JH, Park SH. Bilateral metallic stenting in malignant hilar obstruction. Clin Endosc. 2014;47:440-6.

34. Lee BH, Choe DH, Lee JH, Kim KH, Chin SY. Metallic stents in malignant biliary obstruction: prospective longterm clinical results. Am J Roentgenol1997;168:741-745.

35. Murphy BL, Mueller PR. Metallic biliary stents: technical 
points on optimizing results. Semin Intervent Radiol. 1996;13:55-67.

36. Lee MJ, Dawson SL, Mueller PR, et al. Percutaneous management of hilar biliary malignancies with metallic endoprostheses: results, technical problems, and causes of failure. Radiographics. 1993;13:1249-1263.

37. Gordon RL, Ring EJ, LaBerge JM, Doherty MM. Malignant biliary obstruction: treatment with expandable metallic stents-follow up of 50 consecutive patients. Radiology. 1992;182:697-701.

38. Lee DH, Yu JS, Hwang JC, Kim KH. Percutaneous placement of self-expandable metallic biliary stents in malignant extrahepatic strictures: indications of transpapillary and suprapapillary methods. Korean $J$ Radiol. 2000;1(2):65-72.

39. Jo JH, Park BH. Suprapapillary versus Transpapillary Stent Placement for Malignant Biliary Obstruction: Which is Better? J Vasc Interv Radiol. 2015;26:573-582.

40. Lee M, Dawson SL, Mueller PR, et al.Failed metallic biliary stents: causes and management of delayed complications. Clin Radiol. 1994;49:857-862.

41. Morgan RA, Adam AN. Malignant biliary disease: percutaneous interventions. Tech Vasc Interv Radiol. 2001;4:147-52.

42. Stoker J, Lameris JS. Complications of percutaneously inserted biliary Wallstents. J Vasc Intervent Radiol. 1993;4:767-772.

43. Ridtitid W, Rerknimitr R, Janchai A, Kongkam P, Treeprasertsuk S, Kullavanijaya P. Outcome of second interventions for occluded metallic stents in patients with malignant biliary obstruction. Surg Endosc. 2010;24:221620.

44. Archer SB, Brown DW, Smith CD, Branum GD, Hunter JG. Bile duct injury during laparoscopic cholecystectomy: results of a national survey.AnnSurg 2001;234(4):549-58.

45. Costamagna G, Boškoski I. Current treatment of benign biliary strictures.Annals of Gastroenterology : Quarterly Publication of the Hellenic Society of Gastroenterology. 2013;26(1):37-40.

46. Gwon DI, Laasch HU. Radiological approach to benign biliary strictures. Gastrointestinal Intervention. 2015;4:914.

47. Bonnel DH, Fingerhut AL. Percutaneous transhepatic balloon dilatation of benign bilioenteric strictures: long- term results in 110 patients. Am J Surg. 2012;203(6):67583.

48. Kulkarni CB, Pullara SK, Moorthy S, Prabhu NK, Nazar PK, ,Kannan RR. Percutaneous transhepatic balloon dilatation of benign bilioenteric strictures: Analysis of technique and long-term outcome. Gastrointestinal Intervention. 2015;4:112-119.

49. DePietro DM, Shlansky-Goldberg RD, Soulen MC, et al. Long-term outcomes of a benign biliary stricture protocol. J Vasc Interv Radiol. 2015;26(7):1032-9.

50. Gwon DI, Shim HJ, Kwak BK. Retrievable biliary stent-graft in the treatment of benign biliary strictures. J Vasc Interv Radiol. 2008;19:1328-35.

51. Gwon DI, Ko GY, Ko HK, Yoon HK, Sung KB. Percutaneous transhepatic treatment using retrievable covered stents in patients with benign biliary strictures:mid-term outcomes in 68 patients. Dig Dis Sci. 2013;58:3270-9.

52. Kaufman SL, Kadir S, Mitchell SE, et al. Percutaneous transhepatic biliary drainage for bile leaks and fistulas. $\mathrm{Am}$ J Roentgenol. 1985;144:1055-1058.

53. Ernst O, Sergent G, Mizrahi D, Delemazure O, L'Herminé C. Biliary leaks: treatment by means of percutaneous transhepatic biliary drainage. Radiology. 1999;211(2):3458.

54. Gwon DI, Ko GY, Sung KB, Kim JH, Yoon HK.Percutaneous transhepatic treatment of postoperative bile leaks: prospective evaluation of retrievable covered stent. J VascInterv Radiol. 2011;22(1):75-83.

55. Kawano Y, Mizuta K, Hishikawa S, et al. Rendezvous penetration method using double-balloon endoscopy for complete anastomosis obstruction of hepaticojejunostomy after pediatric living donor liver transplantation. Liver Transpl. 2008;14:385-387.

56. Matlock J, Freeman ML. Endoscopic therapy of benign biliary strictures. Rev Gastroenterol Disord. 2005;5:206214.

57. Chang JH, Lee IS, Chun HJ, et al. Usefulness of the rendezvous technique for biliary stricture after adult rightlobe living-donor liver transplantation with duct-to-duct anastomosis. Gut Liver. 2010;4:68-75.

58. Chang JH, Lee IS, Chun HJ, et al. Comparative study of rendezvous techniques in post-liver transplant biliary stricture. World J Gastroenterol. 2012;18:5957-5964. 